\title{
CROMATOGRAFANDO EM COLUNA COM RESINA DE ALMÉCEGA: UM PROJETO PARA QUÍMICA ORGÂNICA EXPERIMENTAL
}

Gerardo Magela Vieira Júnior, Adonias Almeida Carvalho, Wellington de Abreu Gonzaga ${ }^{\dagger}$ e Mariana H. Chaves*

Departamento de Química, Universidade Federal do Piauí, 64049-550 Teresina - PI, Brasil

Recebido em 28/11/05; aceito em 23/6/06; publicado na web em 19/1/07

\begin{abstract}
COLUMN CHROMATOGRAPHY WITH ALMÉCEGA RESIN: A PROJECT FOR EXPERIMENTAL ORGANIC CHEMISTRY. The use of natural products to demonstrate the silica gel column chromatography technique is proposed in the present article. It describes the separation of the triterpenes $\alpha$ - and $\beta$-amirin from the diol breine and maniladiol, obtained from almécega resin (Protium heptaphyllum March.). The experiment uses an accessible material, was accomplished in $4 \mathrm{~h}$, and can be applied with success an the experimental course of organic chemistry for undergraduate students.
\end{abstract}

Keywords: chemical teaching; resin of almécega; $\alpha$ - and $\beta$-amirin.

\section{INTRODUÇÃO}

Os métodos de separação são freqüentemente abordados em livros de experimentos adotados em disciplinas de química orgânica experimental ${ }^{1-5}$. Dentre eles, destaca-se a cromatografia, constituída de um conjunto de procedimentos que vão desde as técnicas simples de bancadas aos métodos instrumentais sofisticados ${ }^{1,6,7}$.

Diversos experimentos envolvendo ensaios cromatográficos usando giz ${ }^{8}$, gel de sílica ${ }^{1-4,9-12}$, alumina ${ }^{2,4}$, mistura de areia e mármore $^{13}$ como fases estacionárias são propostos para analisar princípios ativos de medicamentos ${ }^{2}$, extrato de folhas de espinafre ${ }^{4,8,9}$, tinta de caneta ${ }^{7,13}$, extrato de flores ${ }^{14}$ entre outros.

As técnicas cromatográficas mais utilizadas nas propostas de experimentos são a cromatografia em camada delgada (CCD) de gel de sílica ${ }^{1-4,9,11,12}$ e a cromatografia em papel $(\mathrm{CP})^{7,14}$, aplicadas principalmente na separação de pigmentos de folhas verdes ${ }^{4,9,12}$. A preferência por estas técnicas é devida à simplicidade, facilidade de execução e rapidez, resultando em menor tempo para realização do experimento.

A literatura relata poucos experimentos de cromatografia em coluna para separação de substâncias naturais ${ }^{1,5,15}$, sendo que a maioria usa esta técnica para separar pigmentos sintéticos ${ }^{3,4,11,13,16}$, isômeros de nitrofenol ${ }^{17}$ e princípios ativos de medicamentos ${ }^{2}$. Misturas de pigmentos são freqüentemente preferidas porque a cor permite sinalizar ou visualizar o processo de separação, dispensando análise qualitativa complementar.

Na rotina de laboratórios de Química Orgânica Sintética e de Produtos Naturais, a maioria das separações consiste de misturas de substâncias incolores e, embora a mistura de pigmentos seja mais didática para demonstração do processo cromatográfico, faz-se necessária a busca por experimentos que se aproximem da realidade destes laboratórios.

O presente trabalho teve como objetivos: propor um experimento de cromatografia preparativa em coluna de gel de sílica, para obtenção de duas misturas de triterpenóides, constituídas por amirinas ( $\alpha$ - e $\beta$-amirina) e dióis (breína e maniladiol), a partir da resina de almécega, um material alternativo natural e de baixo cus-

†n memoriam

*e-mail: mariana@ufpi.br to, visando a demonstração de princípios básicos de cromatografia em coluna e, caracterizar as frações correspondentes às misturas de triterpenóides por cromatografia em camada delgada, usando como parâmetros as cores e o fator de retenção $\left(R_{f}\right)$ das manchas apresentadas nas cromatoplacas. $\mathrm{O}$ experimento pode ser perfeitamente executado em uma aula de química orgânica experimental com duração de 4 h.

\section{A resina de almécega}

Protium heptaphyllum March (Burseraceae), conhecida popularmente como almécega, é encontrada na Região Amazônica e também no Piauí, Bahia, Minas Gerais e Goiás ${ }^{18}$. A resina, exsudada do tronco da árvore, é utilizada na fabricação de vernizes e tintas, na calafetagem de embarcações, em cosméticos e em repelentes de insetos. Apresenta algumas indicações terapêuticas, como analgésica, cicatrizante e expectorante e ações antiulcerogênica e antiinflamatória já comprovadas ${ }^{19}$.

A resina da almécega é um sólido branco amorfo, constituído principalmente por substâncias de natureza terpênica ${ }^{20-22}$, apresenta como constituintes majoritários uma mistura de triterpenóides denominados de $\alpha$-amirina e $\beta$-amirina (Figura 1), os quais juntos correspondem a 45,3\% da constituição química da resina, seguido
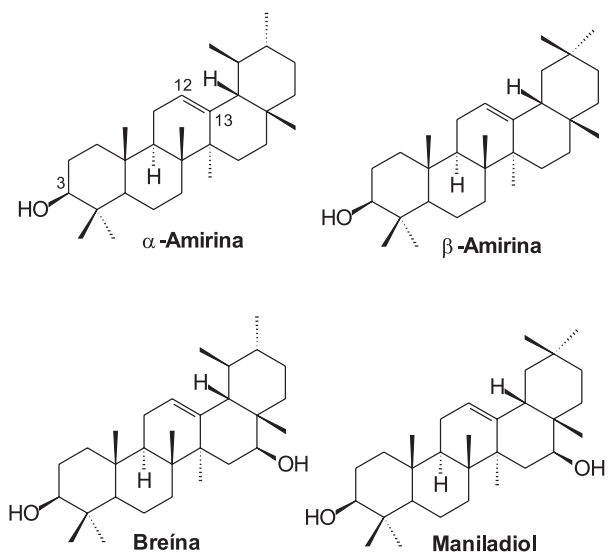

Figura 1. Estruturas dos principais constituintes da resina de almécega 
pela mistura de breína e maniladiol (Figura 1), que respondem por $9,5 \%$. Estas substâncias são triterpernóides pentacíclicos monohidroxilados ( $\alpha$-amirina e $\beta$-amirina) e di-hidroxilados (breína e maniladiol), encontrados em diversas plantas nas mais variadas partes (folhas, flores e caule) ${ }^{20,23}$. Embora os componentes de cada uma destas mistura sejam difíceis de serem separados por técnicas cromatográficas de baixa eficiência, por apresentarem o mesmo fator de retenção em cromatografia em camada delgada, os compostos podem ser identificados facilmente em misturas utilizando espectroscopia de $\mathrm{RMN}^{20,24}$.

\section{PARTE EXPERIMENTAL}

\section{Materiais e reagentes}

Foram utilizados: gel sílica para coluna 0,05-0,2 mm (9 g); iodo; hexano $(240 \mathrm{~mL})$; erlenmeyer de $50 \mathrm{~mL}$; acetato de etila $(40 \mathrm{~mL})$; funil de vidro com haste; suporte universal; bastão de vidro; garra para bureta ou coluna; béquer de $50 \mathrm{~mL}$; coluna de vidro ou bureta de $25 \mathrm{~mL}$; frasquinhos de $8 \mathrm{~mL}$ (25 unidades); algodão; capilares; espátula; cuba cromatográfica; resina de almécega ( $0,3 \mathrm{~g})$; papel de filtro; solução de sulfato cérico ${ }^{10}$; placas cromatográficas de gel de sílica.

\section{Material vegetal}

A resina de almécega foi adquirida no Mercado Central de Teresina - PI, ao preço de R\$10,00 o quilo, proveniente de um almecegal existente no município de Timom-MA.

\section{Empacotamento da coluna}

Prender uma coluna de vidro $(\Phi=10 \mathrm{~mm}, \mathrm{~h}=390 \mathrm{~mm})$ ou bureta de $25 \mathrm{~mL}$ em posição rigorosamente vertical em um suporte universal e colocar um pequeno chumaço de algodão, empurrando-o com um tubo de vidro até a junção do corpo da coluna com a torneira. Este procedimento tem como finalidade não permitir a saída das partículas do adsorvente e permitir o fluxo do eluente. Encher a terça parte da coluna cromatográfica com a mistura de hexano-acetato de etila (9:1). Suspender, em um béquer, $9 \mathrm{~g}$ de gel de sílica para coluna $(0,05-0,2 \mathrm{~mm})$ com quantidade suficiente do eluente, hexanoacetato de etila (9:1), para formar uma mistura espessa e livre de bolhas de ar. Colocar sob a coluna um erlenmeyer de $50 \mathrm{~mL}$, abrir parcialmente a torneira e verter a mistura adsorvente-eluente, com auxílio de um funil, para o interior da coluna, evitando a formação de bolhas de ar e mantendo sempre o adsorvente coberto pelo eluente. Utilizar mais eluente, se necessário, para transferir todo adsorvente. Pode ser usado o próprio eluente recolhido durante a operação de empacotamento.

\section{Aplicação da amostra}

Deixar escoar o eluente da coluna até quase descobrir o adsorvente. Dissolver a resina $(300 \mathrm{mg})$ em cerca de $0,7 \mathrm{~mL}$ de diclorometano e, em seguida adicionar cerca de $673 \mathrm{mg}$ de gel de sílica. Misturar com uma espátula até a evaporação completa do solvente, obtendo-se um material seco e disperso ("farofa"). Com o auxílio de um funil, aplicar na coluna a resina adsorvida no gel de sílica ("farofa"). Colocar pequenas porções do eluente $(0,5 \mathrm{~cm}$ de espessura) e fazê-las escoar até que o líquido sobrenadante, levemente amarelado, permaneça incolor. Desenvolver a cromatografia, recolhendo inicialmente o equivalente ao volume morto da coluna $(15 \mathrm{~mL})$ e, em seguida, coletar frações de aproximadamente $7 \mathrm{~mL}$ em frasquinhos de vidro, tipo penicilina, utilizando como eluentes hexano-acetato de etila 9:1 (frações 1 a 9) e hexano-acetato de etila 8:2 (frações 10 a 25). Monitorar as frações recolhidas, por CCD de gel de sílica.

\section{Monitoramento das frações por CCD}

Aplicar as frações recolhidas, em seqüência alternada, em placas de gel de sílica de $5 \times 10 \mathrm{~cm}$ e desenvolver em cuba contendo a mistura de hexano-acetato de etila (8:2). Revelar as placas borrifando com solução preparada com $1,1 \mathrm{~g}$ de sulfato cérico, dissolvido em 7,5 mL de ácido sulfúrico concentrado e diluído com $400 \mathrm{~mL}$ de água, seguido de aquecimento até o aparecimento das manchas ${ }^{10}$ ou em cuba contendo vapores de iodo. Usar a resina como padrão de comparação. Reunir as frações semelhantes de acordo com a cor e fator de retenção $\left(R_{f}\right)$ apresentados nas cromatoplacas, evaporar o solvente, pesar e determinar o rendimento.

\section{RESULTADOS E DISCUSSÃO}

O eluente escolhido para iniciar a coluna foi a mistura de hexanoacetato de etila (9:1), uma vez que os constituintes menos polares da resina (as amirinas) ficaram distribuídos na placa com $R_{f}$ menor que 0,5 . Este procedimento de escolha do solvente pode ser feito em aula anterior a da realização da cromatografia em coluna, analisando uma solução da resina, em diclorometano, através de CCD de gel de sílica usando como fase móvel hexano-AcOEt em diferentes proporções.

No desenvolvimento da cromatografia em coluna, obtém-se mistura de amirinas ( $\alpha$ - e $\beta$-amirina), na forma de um sólido branco e amorfo, obtida nas frações de 3 a 5 (129 mg, hexano-acetato de etila 9:1). A seguir, obtém-se a mistura de dióis (breína e maniladiol) nas frações de 11 a 13 (37 mg, hexano-acetato de etila 8:2). O rendimento da mistura de amirinas é de cerca de $43 \%$, comparável ao relatado na literatura ${ }^{22}$.

As misturas de amirinas e de dióis aparecem no cromatograma obtido em CCD, revelado com solução sulfato cérico, inicialmente como manchas de cor alaranjada, que após um período de 15 min se tornam rosa $\left(R_{f}=0,46\right)$ e verde $\left(R_{f}=0,29\right)$, respectivamente (Figura 2$)$.

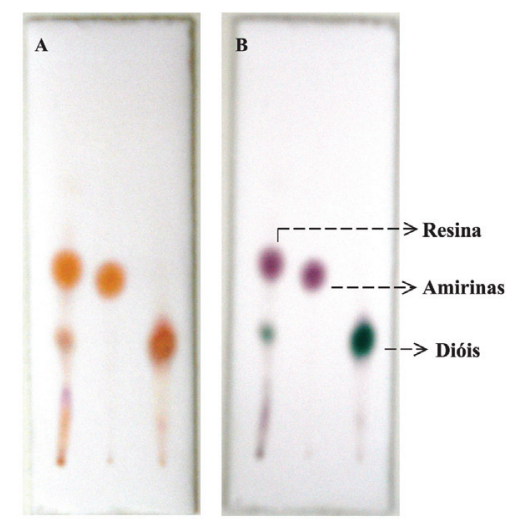

Figura 2. Cromatograma em camada delgada de gel de sílica. Eluente: hexano-acetato de etila (8:2); revelador: solução de sulfato cérico; A: imediatamente após a revelação, $\boldsymbol{B}: 15$ min. após a revelação; Amirinas: $\alpha$ e $\beta$-amirina; Dióis: breína e maniladiol

Os constituintes químicos das duas misturas tiveram suas estruturas confirmadas pela análise dos espectros de $\mathrm{RMN}{ }^{1} \mathrm{H} \mathrm{e}{ }^{13} \mathrm{C}$ e comparação com dados da literatura ${ }^{20,22}$.

No presente experimento, o professor pode abordar aspectos 
relevantes da cromatografia em coluna, tais como escolha da fase estacionária e fase móvel, relação amostra/fase estacionária, empacotamento e volume morto da coluna ${ }^{1,25}$. Em relação ao fracionamento da resina pode discutir a ordem de eluição das substâncias, ressaltando o número de hidroxilas em suas estruturas e a interação destas com sílica. Pode também chamar atenção para a dificuldade de resolução das amirinas ou dos dióis por cromotografia de baixa eficiência, uma vez que a diferença estrutural entre $\alpha$ - e $\beta$-amirina ou entre breína e maniladiol está na mudança de posição de uma metila no anel E.

O transporte das condições de eluição da amostra da coluna para a análise subseqüente em CCD é um outro aspecto que pode ser discutido. Em geral, se a amostra foi eluída da coluna em uma mistura de solvente na proporção de 9:1, na realização da CCD, recomenda-se duplicar a quantidade do solvente mais polar e diminuir na mesma proporção o solvente menos polar, passando a 8:2.

Alternativamente, o experimento pode ser complementado incluindo, como atividade, a análise dos espectros de IV, RMN ${ }^{1} \mathrm{H}$ e ${ }^{13} \mathrm{C}$ das frações correspondentes às misturas de $\alpha$-e $\beta$-amirina e de breína e maniladiol, mostrando a aplicação da metodologia de identificação de misturas de triterpenos ${ }^{24}$ e fazer a atribuição completa dos deslocamentos químicos dos sinais dos espectros de $\mathrm{RMN}{ }^{13} \mathrm{C}$, por comparação com dados registrados na literatura ${ }^{20,22}$. Pode também calcular a porcentagem de cada constituinte nas misturas, através da comparação da integração dos sinais dos hidrogênios carbinólicos e olefínicos do espectro de $\mathrm{RMN}{ }^{1} \mathrm{H}^{22}$, usando a seguinte expressão: $\%=\left(\mathrm{A}_{1} \times 100\right) / \mathrm{A}_{\mathrm{T}}$, onde $\mathrm{A}_{1}$ representa a área integrada do sinal de $\mathrm{H}-13$ [ $\delta 5,15$ ( $\alpha$-amirina); $\delta$ 5,20 ( $\beta$-amirina); $\delta$ 5,21 (breína) e $\delta 5,27$ (maniladiol)] e $\mathrm{A}_{\mathrm{T}}$ representa a área integrada do sinal de $\mathrm{H}-3$, que aparece para os dois triterpenóides em cada mistura, na mesma região do espectro $\mathrm{RMN}{ }^{1} \mathrm{H}$, ou seja, aproximadamente em $\delta 3,24$ (dd, $J=5$ e $11 \mathrm{~Hz}$ ). Outro enfoque a ser explorado seria a utilização das misturas de triterpenóides, obtidos da resina, para realização de reações de acetilação e oxidação, visando a obtenção e caracterização dos derivados sintéticos.

\section{CONCLUSÃO}

O presente artigo abordou o método de separação por cromatografia, focalizando as técnicas em placas e em coluna, com a elaboração de um roteiro para aulas práticas de química orgânica, a ser executado em $4 \mathrm{~h}$. Foi proposta como amostra a ser separada a resina de almécega, um produto natural de baixo custo, comercializado por erveiros.

A separação de produtos naturais é ainda pouco explorada em aulas experimentais, em função da natureza complexa destes materiais, demandando um grande consumo de tempo para realização de experimentos, sobretudo os de cromatografia em coluna. A resina de almécega é um material amorfo, livre de clorofilas e polifenóis, contém pouco carboidrato e materiais graxos (triglicerídeos e ácidos graxos), dispensando tratamentos prévios, tais como extração e/ou partição, utilizados comumente antes de fracionamentos e purificação de produtos naturais por cromatografia em coluna.

\section{AGRADECIMENTOS}

Pelas bolsas de A. A. Carvalho (Iniciação Científica - UFPI), G. M. Vieira Jr. (Mestrado - CNPq), W. A. Gonzaga (DCR - CNPq/ FAPEPI) e apoio financeiro (CAPES/PROCAD, FINEP e CNPq)

\section{REFERÊNCIAS}

1. Collins, C. H.; Braga, G. L.; Bonato, P. S.; Introdução a Métodos Cromatográficos, 6 ${ }^{\mathrm{a}}$ ed., Ed. da Unicamp: Campinas, 1997.

2. Pavia, D. L.; Lampmam, G. M.; Kriz, G. S.; Engel, R. G.; Introduction to Organic Laboratory Techniques: a microscale approach, $3^{\text {rd }}$ ed., Saunders College Publishing: Phyladelphia, 1998.

3. Soares, B. G.; Sousa, N. A.; Pires, D. X.; Química Orgânica: teoria e técnicas de preparação, purificação e identificação de compostos orgânicos, Guanabara: Rio de Janeiro, 1988.

4. Roberts, R. M.; Gilbert, J. C.; Rodewald, L. B.; Wingrove, A. S.; Modern Experimental Organic Chemistry, $4^{\text {th }}$ ed., Saunders College Publishing: Philadelphia, 1985

5. Ikan, R.; Natural Product: a laboratory guide, $2^{\text {nd }}$ ed., Academic Press: San Diego, 1991.

6. Degani, A. L. G.; Cass, Q. B.; Vieira, P. C.; Química Nova na Escola 1998, $\mathrm{n}^{\circ} 7,25$.

7. Lisbôa, J. C. F.; Química Nova na Escola 1998, nº 7, 38.

8. Oliveira, A. R. M.; Simonelli, F.; Marques, F. A.; Química Nova na Escola 1998, $n^{\circ} 7,37$.

9. Quach, H. T.; Steeper, R. L.; Griffin, G. W.; J. Chem. Educ. 2004, 81, 385.

10. Chaves, M. H.; Quim. Nova 1997, 20, 560.

11. Reynolds, R. C.; O’Dell, C. A.; J. Chem. Educ. 1992, 69, 989.

12. Bessler, K. E.; Neder, A. V. F.; Química em Tubos de Ensaio: uma abordagem para principiantes, Edgard Blücher: São Paulo, 2004.

13. Celeghini, R. M. S.; Ferreira, L. H.; Química Nova na Escola 1998, nº 7 , 39.

14. Okumura, F.; Soares, M. H. F. B.; Cavalheiro, E. T. G.; Quim. Nova 2002, 25,680 .

15. Kimbrough, D. R.; J. Chem. Educ. 1992, 69, 987.

16. Wigman, L. S.; Kelsch, C. T.; J. Chem. Educ. 1992, 69, 991.

17. Imamura, P. M.; Baptistella, L. H. B.; Quim. Nova 2000, 23, 270.

18. Corrêa, M. P.; Dicionário das Plantas Úteis do Brasil, Imprensa Nacional: Rio de Janeiro, 1926, vol. 1.

19. Oliveira, F. A.; Vieira-Júnior, G. M.; Chaves, M. H.; Almeida, F. R. C.; Florêncio, M. G.; Lima-Júnior, R. C. P.; Silva, R. M.; Santos, F. A.; Rao, V. S. N.; Pharmacol. Res. 2004, 49, 105; Oliveira, F. A.; Vieira-Júnior, G. M.; Chaves, M. H.; Almeida, F. R. C.; Santos, K. A.; Martins, F. S.; Silva, R. M.; Santos, F. A.; Rao, V. S. N.; Planta Med. 2004, 70, 780; Siani, A. C.; Ramos, M. F. S.; de Lima, O. M.; Santos, R. R.; Ferreira, E. F.; Soares, R. O. A.; Rosas, E. C.; Susunaga, G. S.; Guimarães, A. C.; Zoghbi, M. G. B.; Henriques, M. G. M. O.; J. Ethnopharmacol. 1999, 57, 66.

20. Maia, R. M.; Barbosa, P. R.; Cruz, F. G.; Roque, N. F.; Fascio, M.; Quim. Nova 2000, 23, 623 .

21. Sussunaga, G. S.; Siani, A. C.; Pizzolatti, M. G.; Yunes, R. A.; Delle Monache, F.; Fitoterapia 2001, 72, 709.

22. Vieira Jr., G. M.; Chaves, M. H.; Souza, C. M. L.; Quim. Nova 2005, $28,183$.

23. Lopes, M. N.; Oliveira, A. C.; Young, M. C. M.; Bolzani, V. S.; J. Braz. Chem. Soc. 2004, 15, 468; Galotta, A. L. Q.; Boaventura, M. A. D.; Quim. Nova 2005, 28, 610; Kundakovic, T.; Fokialakis, N.; Magiatis, P.; Kovacevic, N.; Chinou, L.; Chem. Pharm. Bull. 2004, 52, 1462; Ukiya, M.; Akihisa, T.; Tokuda, H.; Suzuki, H.; Mukainaka, T.; Ichiishi, E.; Yasukawa, Y.; Kasahara, Y.; Nishino, H.; Cancer Lett. 2002, 177, 7.

24. Olea, R. S. G.; Roque, N. F.; Quim. Nova 1990, 13, 278.

25. Matos, F. J. A.; Introdução à Fitoquímica Experimental, 2a ed., Edições UFC: Fortaleza, 1997. 